\title{
Knowledge and Practicing Behavior Related to Personal Hygiene among the Secondary School Students of Mymensingh Sadar Upazilla, Bangladesh
}

\author{
Jayanta Kumar Ghose ${ }^{1}$, Md. Mahfuzar Rahman², Jayedul Hassan ${ }^{3 *}$, Md. Shahidur Rahman Khan ${ }^{3}$ and \\ Muhammad Ashiqul Alam ${ }^{3}$ \\ ${ }^{1}$ Residential Medical Officer, Muktagacha Upazilla Health Complex, Mymensingh, Bangladesh. \\ ${ }^{2}$ Department of Community Medicine, NIPSOM, Mohakhali, Dhaka, Bangladesh. \\ ${ }^{3}$ Department of Microbiology and Hygiene, Bangladesh Agricultural University, Mymensingh-2202. Bangladesh. \\ *Corresponding author's e-mail: dr_jahid@bau.edu.bd
}

[Received: 11 April 2012, Revised: 06 June 2012, Accepted: 30 June 2012]

\begin{abstract}
A B S T R A C T
A descriptive type of cross sectional study was conducted on 132 students of class IX and X of Mymensingh sadar upazilla during early April to late June, 2007. This study was performed to assess and compare the level of knowledge and practicing behavior of urban and rural students in regards to hand washing, bathing, tooth brushing and taking care of nail and hair. All the students were interviewed with a semi-structured questionnaire and observed with an observational check list. The mean age of the students was $14.5 \pm 0.94$ years. The knowledge of the students regarding tube well water for drinking was significantly higher in rural area $(98.3 \%)$ compared to urban area. In addition, tube well water was stated as safe for bathing by $77.3 \%$ and safe for washing by $80.3 \%$ students. Hand washing before meal with soap and water was found almost similar among urban and rural students but hand washing with soap and water after defecation was found significantly better practiced in urban (97.2\%) students. Practice regarding tooth paste use was higher in urban (80.6\%) area and charcoal use $(10.0 \%)$ was still found in rural areas. The mean frequency of tooth brushing was significantly

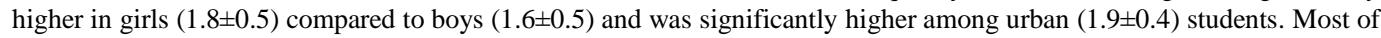
the students were found trimming their nail once a week $(74.2 \%)$ and cut their hair once a month $(85.6 \%)$. Overall trend of knowledge and practice about personal hygiene is in positive direction but urban students and girls were more aware about personal hygiene than rural students.
\end{abstract}

Keywords: Knowledge, Practice, Behavior, Secondary school, Students, Personal hygiene

C 2012 Microbes and Health. All rights reserved

\section{Introduction}

Personal hygiene is the science of healthy-living of an individual. The term personal hygiene includes all those personal factors, which influence the health and wellbeing of an individual. It comprises a broad range of day to day activities such as bathing, clothing, washing hands and toilet; care of nails, feet and teeth; spitting, coughing, sneezing, personal appearance and inculcation of clean habits. Training in personal hygiene should begin at a very early age and must be carried through school age. Snow et al. (2008) reported that children with proper hand washing practices are less likely to report gastrointestinal and respiratory symptoms. In addition, hand washing with soap has been reported to reduce diarrheal morbidity by $44 \%$ and respiratory infections by 23\% (Curtis et al., 2009). Therefore, it is clearly evident that the aim of personal hygiene is not only to promote the standards of personal cleanline-

Supplemental materials are available at- http://journal.bsvmph.org/

To cite this article: JK Ghose, MM Rahman, J Hassan, MSR Khan and MA Alam, 2012. Knowledge and practicing behavior related to personal hygiene among the secondary school students of Mymensingh sadar upazilla, Bangladesh, 1(1): 34-37. ss within the setting of the condition where people live, but also to reduce the prevalence and incidence of communicable diseases.

Personal habits are discrete and independently modifiable. Individuals can voluntarily alter such behavior to maintain good personal hygiene. One of the main problems of Bangladesh is illiteracy. Forty four percent people of Bangladesh are reportedly illiterate (UNDP, 2011). It is unknown to them that simply practice of hand washing and provision of potable drinking water in adequate quantity can eliminate most water borne and water related diseases (Rashid et al., 2004). Since about $90 \%$ of infections are carried to the body through the mouth with water, food, dirt etc., the importance of personal cleanliness and clean habits is obvious (Ghosh, 1969).

In Bangladesh, there are 18,756 secondary schools in which 17.191 million students are enrolled (BANBEIS, 2008). School as socializing institution for children and adolescents play a vital role in the development of healthy citizen. When the students are introduced with knowledge of personal hygiene and life style as they mature, they are in a better position as adult to maintain their own health 
and influence the health of the family. School health education program can play a vital role in changing health behavior of the people. Health management can easily be spread into the family, community through the school students. The present study was conducted among the secondary school students with a view to find out the status of personal hygiene among urban and rural students in terms of knowledge and practice and being intended to support a change of the role of the community from passive recipient to active participation in health development process by identifying their own problems.

\section{Materials and Methods}

This descriptive type of cross sectional study was conducted on the students of class IX and X in Police line high school (urban), Police line, Mymensingh city and in Kaunia high school (rural), Kaunia village, Sadar upazilla, Mymensingh, during the period from April to June, 2007. Total 132 students of the two secondary schools were selected purposively. A semi-structured questionnaire and observational checklist were used for collection of data (Supplemental material). A draft questionnaire was developed according to the objectives of this study. Prior to data collection the questionnaire was pretested and after that it was modified and finalized. Data were collected by face to face interviewing the students using the developed semi-structured questionnaire. Direct observation on physical appearance of the students were done and recorded in a checklist. All the collected data were checked, verified and edited and then analyzed (Chi square test) using statistical package for social science (SPSS version 11.5) with $95 \%$ level of confidence $(p<0.05)$.

\section{Results}

Among the 132 students enrolled in Police line high school (urban) and Kaunia high school (rural), 51.5 and $48.5 \%$ students belonged to class nine and class ten respe- ctively (Table 1). Based on gender $47.7 \%$ students were boys and $52.3 \%$ students were girls. The mean age was $14.5 \pm 0.94$ years (Table 4). The literacy rate of their parents e.g., fathers and mothers were 81.8 and $69.7 \%$, respectively. In urban and rural area 9.7 and $28.3 \%$ fathers of the students were illiterate, respectively (Table 2). Similarly regarding the mother's education, 19.4 and $43.3 \%$ were illiterate in urban and rural area, respectively (Table $2)$. Fathers and mothers illiteracy was significantly $(p<0.05)$ higher in rural area compared to urban areas' student.

Regarding the knowledge on the use of safe water, 93.2, 77.3 and $80.3 \%$ respondents mentioned tube well water as a source of safe water for drinking, bathing and washing, respectively (Table 2). Nearly eighty percent $(79.5 \%)$ respondents mentioned that soap and water should be used for hand washing before meal, $90.9 \%$ stated that soap and water should be used to clean hand after defecation (Table 2). In respect of personal cleanliness $99.2 \%$ respondents washed their hand before taking meal, $97.7 \%$ took bath daily and $100 \%$ had habit of daily tooth brushing, $64.4 \%$ brush their teeth 2 times daily, $59.1 \%$ used tooth paste, $32.6 \%$ tooth powder, $4.5 \%$ charcoal and $3.8 \%$ meswak (Table 2 and 3). In the current study, the mean frequency of tooth brushing was $1.6 \pm 0.5$ in boys and $1.8 \pm 0.5$ in girls. The mean difference of tooth brushing was significantly $(p<0.05)$ higher in girls compared to boys. Similarly, the mean frequency of tooth brushing was also found significantly $(p<0.05)$ higher in urban compared to rural students (Table 4).

\section{Table 1: Distribution of the respondents}

\begin{tabular}{lccccccc}
\hline & \multicolumn{2}{c}{ Urban } & \multicolumn{2}{c}{ Rural } & \multicolumn{2}{c}{ Total } & \\
\hline & $\mathrm{n}$ & $\%$ & $\mathrm{n}$ & $\%$ & $\mathrm{n}$ & $\%$ & $P$ value \\
\cline { 2 - 9 } Class IX & 36 & 50 & 32 & 53.3 & 68 & 51.5 & \\
Class X & 36 & 50 & 28 & 46.7 & 64 & 48.5 & 0.702 \\
\hline Total & 72 & 100 & 60 & 100 & 132 & 100 & \\
\hline
\end{tabular}

Table 2: Comparison between urban and rural secondary school in some selected variables

\begin{tabular}{|c|c|c|c|c|c|c|}
\hline \multirow[t]{2}{*}{ Variables } & \multicolumn{2}{|c|}{$\begin{array}{l}\text { Urban } \\
(\mathrm{N}=72)\end{array}$} & \multicolumn{2}{|c|}{$\begin{array}{c}\text { Rural } \\
(\mathrm{N}=60)\end{array}$} & \multirow[t]{2}{*}{$\begin{array}{c}\text { Total } \\
\text { (Urban+Rural) }\end{array}$} & \multirow[t]{2}{*}{$P$ Value } \\
\hline & $\mathrm{n}$ & $\%$ & $\mathrm{n}$ & $\%$ & & \\
\hline \multicolumn{7}{|l|}{ Socio demography } \\
\hline Fathers education (illiterate) & 7 & 9.7 & 17 & 28.3 & 18.2 & $0.005^{\mathrm{s}}$ \\
\hline Mothers education (illiterate) & 14 & 19.4 & 26 & 43.3 & 30.3 & $0.003^{\mathrm{s}}$ \\
\hline \multicolumn{7}{|l|}{ Knowledge } \\
\hline Tube well water (drinking) & 64 & 88.9 & 59 & 98.3 & 93.2 & $0.039^{\mathrm{s}}$ \\
\hline Tube well water (bathing) & 52 & 72.2 & 50 & 83.3 & 77.3 & $0.129^{\mathrm{ns}}$ \\
\hline Tube well water (washing) & 58 & 80.6 & 48 & 80.0 & 80.3 & $0.752^{\text {ns }}$ \\
\hline Tap water (drinking) & 8 & 11.1 & 0 & 0.0 & 6.1 & $0.007^{\mathrm{s}}$ \\
\hline Tap water (bathing) & 16 & 22.2 & 0 & 0.0 & 12.1 & $0.001^{\mathrm{s}}$ \\
\hline Tap water (washing) & 12 & 16.7 & 0 & 0.0 & 9.1 & $0.001^{\mathrm{s}}$ \\
\hline \multicolumn{7}{|l|}{ Hand washing before meal } \\
\hline Soap and water & 58 & 80.6 & 47 & 78.3 & 79.5 & $0.752^{\text {ns }}$ \\
\hline Only water & 14 & 19.4 & 12 & 20.0 & 19.7 & $0.936^{\mathrm{ns}}$ \\
\hline \multicolumn{7}{|l|}{ Hand washing after defecation } \\
\hline Soap and water & 70 & 97.2 & 50 & 83.3 & 90.9 & $0.005^{\mathrm{s}}$ \\
\hline Soil and water & 2 & 2.8 & 6 & 10.0 & 6.1 & $0.140^{\mathrm{ns}}$ \\
\hline Ashes and water & 3 & 4.2 & 4 & 6.7 & 5.3 & $0.701^{\mathrm{ns}}$ \\
\hline \multicolumn{7}{|l|}{ Practice: tooth brushing } \\
\hline Tooth paste & 58 & 80.6 & 20 & 33.3 & 59.1 & $0.001^{\mathrm{s}}$ \\
\hline Tooth powder & 13 & 18.1 & 30 & 50.0 & 32.6 & $0.001^{\mathrm{s}}$ \\
\hline Charcoal & 0 & 0.0 & 6 & 10.0 & 4.5 & $0.007^{\mathrm{s}}$ \\
\hline Meswak & 1 & 1.4 & 4 & 6.7 & 3.8 & $0.176^{\mathrm{ns}}$ \\
\hline Cleaning hair (Shampoo) & 66 & 91.7 & 45 & 75.0 & 84.1 & $0.009^{\mathrm{s}}$ \\
\hline
\end{tabular}


Among the students 74.2 and $85.6 \%$ trim their nails once a week and cut their hair once a month, respectively (Table 5).

\section{Discussion}

The literacy rate and women education in Bangladesh is growing up gradually due to ongoing awareness among government and NGOs (Bangla, 2000) and the literacy rate of parents as found in this study is higher than that of national standard (55.9\%) as reported by UNDP (2011). The participation of boys and girls in secondary education observed here is similar to the findings of Begum (2000), who conducted her study in Rotary School and Provati School in Khalishpur at Khulna and reported the participation of boys and girls as 46.4 and $53.6 \%$, respectively with the mean age of 14.56 years.

In the present study, a trend in increase in the knowledge of the students regarding personal hygiene was observed. In addition, the knowledge of the students regarding the source of safe water for drinking, bathing and washing as documented in this study was found higher than the previous study reported by Begum (2000) in Rotary school and Provati School in Khalishpur at Khulna. This
Table 3: Distribution of respondents by their hand washing, bathing and tooth brushing

\begin{tabular}{|c|c|c|}
\hline Habits & $\begin{array}{l}\text { Respondents } \\
(\mathrm{n}=132)\end{array}$ & $\%$ \\
\hline \multicolumn{3}{|l|}{$\begin{array}{l}\text { 1. Hand washing } \\
\text { (before taking meal and after } \\
\text { defecation) }\end{array}$} \\
\hline Wash & 131 & 99.2 \\
\hline Don't wash & 1 & 0.8 \\
\hline \multicolumn{3}{|l|}{ 2. Bath } \\
\hline Daily & 129 & 97.7 \\
\hline Not daily & 3 & 2.3 \\
\hline \multicolumn{3}{|l|}{ 3. Tooth brushing } \\
\hline \multicolumn{3}{|l|}{ Frequency } \\
\hline Once/day & 41 & 31.1 \\
\hline Twice/day & 85 & 64.4 \\
\hline Thrice/day & 6 & 4.5 \\
\hline \multicolumn{3}{|l|}{ Time } \\
\hline $\begin{array}{l}\text { After rising from the } \\
\text { bed at the morning }\end{array}$ & 117 & 89.3 \\
\hline $\begin{array}{l}\text { Before going to bed } \\
\text { at night }\end{array}$ & 83 & 63.4 \\
\hline After breakfast & 16 & 12.2 \\
\hline After every meal & 4 & 3.1 \\
\hline
\end{tabular}

Table 4. Association of age, family members and frequency of tooth brushing

\begin{tabular}{|c|c|c|c|c|c|c|}
\hline \multirow[t]{2}{*}{ Parameters } & Urban & Rural & \multirow{2}{*}{$P$ value } & Boys & Girls & \multirow{2}{*}{$P$ value } \\
\hline & Mean \pm SD & Mean \pm SD & & Mean \pm SD & Mean \pm SD & \\
\hline Age & $14.5 \pm 0.73$ & $14.6 \pm 1.15$ & $0.616^{\text {ns }}$ & $14.7 \pm 0.96$ & $14.3 \pm 0.90$ & $0.031^{\mathrm{s}}$ \\
\hline Family members & $5.2 \pm 1.40$ & $6.3 \pm 1.50$ & $0.001^{\mathrm{s}}$ & $5.3 \pm 1.4$ & $6.1 \pm 1.60$ & $0.007^{\mathrm{s}}$ \\
\hline Frequency of tooth brushing & $1.9 \pm 0.40$ & $1.7 \pm 0.60$ & $0.001^{\mathrm{s}}$ & $1.6 \pm 0.5$ & $1.8 \pm 0.50$ & $0.041^{\mathrm{s}}$ \\
\hline
\end{tabular}

ns $=$ Not significant, $\mathrm{s}=$ Significant

may be due to increased awareness among people about personal hygiene and government initiatives through print and electronic media.

The knowledge and practicing behavior of the students regarding hand washing before taking meal and after defecation and use of soap and water for washing hand was found close to the finding of Yalcin et al. (2004) and Vivas et al. (2010) and higher than the findings of Begum (2000). Yalcin and colleagues (2004), in their study found that $99.2 \%$ of the adolescent students (first grade) use soap and water for washing hand before taking meal and after defecation. Vivas et al. (2010) reported in their study that most students washed their hands before meals $(99.0 \%)$, but only $36.2 \%$ used soap, whereas Begum (2000) found that 33.93 and $77.68 \%$ students used soap and water for hand washing before taking meal and after defecation, respectively.

In the present study, more students $(97.7 \%)$ were found to take bath daily compared to the earlier work of Rahman (2001), who performed a study regarding the practice of personal hygiene among school going and non-school going students in Voberchar Owagir Ali High School of Munsiganj district in 2001 and found $85.83 \%$ took bath daily. As stated earlier, this increased tendency of students to take bath daily in recent years could be related with the increased awareness among the parents about personal hygiene.
Table 5. Distribution of the respondents by frequency of nail trimming and hair cut $(n=132)$

\begin{tabular}{llcc}
\hline Parameter & Interval & $\begin{array}{c}\text { Respondents } \\
(\mathbf{n = 1 3 2})\end{array}$ & $\%$ \\
\hline Nail trimming & Once a week & 98 & 74.2 \\
& At any time & 31 & 23.5 \\
& Fortnightly & 3 & 2.3 \\
\hline Hair cutting & Once a month & 113 & 85.6 \\
& After every 2-month & 17 & 12.9 \\
& Once a week & 2 & 1.5 \\
\hline
\end{tabular}

Here, the frequency of tooth brushing was found higher $(1.8 \pm 0.5)$ in girls compared to boys as reported by $\mathrm{Al}-$ Ansari (2007). He also reported twice-a-day tooth brushing frequency among female students and often much more compared to boys. A slightly less in tendency to trim the nail as a prerequisite for better personal hygiene was found among the students in the present study compared to those reported by Rahman (2001), who conducted his study in Vopberchar Owagir Ali High School of Munsigonj district and found that $93.33 \%$ students trimmed their nail once a week and $6.67 \%$ once a month. However, present study was carried out on a small population in a particular area. Hence, further in-depth study across the whole country involving more population may reflect the actual scenario. 


\section{Conclusion}

An increase in the trend of knowledge and practice about personal hygiene was observed among the school students with some exceptions.

\section{References}

Al-Ansari JM and S Honkala, 2007. Gender differences in oral health knowledge and behavior of the health science college students in Kuwait. J Allied Health, 36: 41-46.

BANBEIS, 2008. (http://www.banbeis.gov.bd/db_bb/ secondary_education_1.htm)

Bangla, 2000. (http://www.bangla2000.com/bangladesh/ education.shtm)

Begum S, 2000. Knowledge regarding personal hygiene among the students and hygienic status of two selected secondary schools. Dhaka (NIPSOM): Bangladesh.

Curtis VA, LO Danquah and RV Aunger, 2009. Planned, motivated and habitual hygiene behaviour: an eleven country review. Health Educ Res, 4: 655-673.
Ghosh BN, 1969. Treatise on hygiene and Public Health, Scientific Publishing Company, $11^{\text {th }}$ Ed, pp: 320.

Rahman A, 2001. A study on practice regarding personal hygiene among school going and non- school going children in a selected rural area. Dhaka (NIPSOM): Bangladesh.

Rashid KM, MD Khabiruddin and H sayeed, 2004. Text Book of Community Medicine and Public health, RKH Publishers, $4^{\text {th }}$ Ed, pp: 309.

Snow M, GL White and HS Kim, 2008. Inexpensive and time-efficient hand hygiene interventions increase elementary school children's hand hygiene rates. J Sch Health, 78: 230-233.

UNDP. 2011. List of Countries by Literacy rate, United Nations Development Programme Report, 2011.

Vivas A, G Bizu, A Nigusu, K Abera, B Yemane, and MA Williams, 2010. Knowledge, Attitudes, and Practices (KAP) of Hygiene among School Children in Angolela, Ethiopia. J Prev Med Hyg, 51: 73-79.

Yalçin SS, S Yalçin and S Altin, 2004. Hand washing and adolescents, A study from seven schools in Konya, Turkey. Int J Adolesc Med Health, 16: 371-376. 